\title{
Shape Up or Shape Out: The Case of Lecturers Unfit for the Modern Classroom
}

\author{
Ann Hildah Gatakaa Kinyua ${ }^{1 *} \quad$ Moses Kathuri Njeru $^{2}$ \\ 1.Faculty of Humanities and Social Sciences, Chuka University, P.O Box 109-60400, Chuka, Kenya \\ 2.Faculty of Agricuture and Environmental Studies, Chuka University, P.O Box 109-60400, Chuka, Kenya
}

\begin{abstract}
Sustainable Development Goal (SDG) number four is quality education for all and the Commonwealth Education Report (2019) underscores the central position of this goal in powering the achievement of the entire 2030 agenda. Top among the issues attendant to quality education is quality teachers who are able to function and deliver in line with the principles of the heutagogical approach where learners are considered autonomous and learning is seen as self-determined. However, the majority of instructors serving in Kenyan classrooms at all levels today are products of old, teacher-centred approaches of content delivery and have faithfully carried on the practice to their charges. This situation is aggravated by inadequate or non-existent facilities in the way of technologies that would open up education by means of open delivery not confined to the traditional classroom. All these facts work against the envisaged quality education for all and fail to inspire the global goal of education as a continuous lifelong learning process since the learner is reduced to a consumer of knowledge that has been created elsewhere. These issues are relevant in Kenya, a country that is yet to adopt in serious practice the concept of the Open University. This paper aims to assess the preparedness of Kenyan university lecturers as instructors in an educational platform that is rapidly becoming open, global and technology-based. It also seeks to assess their present abilities or lack there-off to embrace technology to promote their effectiveness as instructors. The study also assesses the lecturers' attitudes towards the paradigm shift and what it means for them as contributors to the achievement of SDG 4. The study will be conducted on a random sample of lecturers from Kenyan universities. The findings of the study will identify gaps and inform policy formulation regarding in-service staff training and development.
\end{abstract}

Keywords: Information Communication Technology (ICT); Technology-Based Instruction (TBI); Open Education Resources (OER); Teacher-centred

DOI: $10.7176 / \mathrm{JEP} / 11-6-26$

Publication date: February $29^{\text {th }} 2020$

\section{Introduction}

Embracing technology is a crucial component of advancement in many sectors of life, including education. As rightly observed by Grabe (2007) technology transforms our societies and totally changes the way people think, work and live. Accordingly, schools and other educational institutions which are supposed to prepare students to live in "a knowledge society" need to consider Information Communication Technology (ICT) integration in their curriculum (Ghavifekr \& Rosdy, 2015). Educational technology encompasses learning theory, computer-based training and online learning to facilitate learning and improving performance by creating, using, and managing appropriate technological processes and resources. Timothy, et al., (2013) observe that there is substantial evidence that incorporating technology of any kind in the classroom as an instructional tool enhances the learning process and maximizes the students' abilities in active learning.

ICT can be used in various ways where it helps both teachers and students to learn about their respective subject areas. A technology-based teaching and learning offers various interesting ways which includes educational videos, stimulation, storage of data, the usage of databases, mind-mapping, guided discovery, brainstorming, music, world wide web (www) that will make the learning process more fulfilling and meaningful (Finger \& Trinidad, 2002). On the other hand, learners will benefit from ICT integration where they are not bound to the limited curriculum and resources, instead hands-on activities in a technology-based course is designed to help them to stimulate their understanding about the subject. It also helps instructors to design their lesson plans in an effective, creative and interesting approach that would result in students' active learning.

Hermans, Tondeur, Van-Braak, and Valcke (2008) have identified three main stages for ICT to be highly valued and regarded by the teachers: integration, enhancement and complementary. Integration approach is about implementing right use of ICT in a particular subject area that involves complex concepts and skills to improve students' achievement and attainment. Besides, the review of curriculum is also needed so that only related ICT resources and appropriate software will be installed for the main aims and objectives of curriculum to be achieved. Enhancement approach is about using ICT to give great emphasis on the topic introduced. For instance, Microsoft PowerPoint can be used to present the topic in a very innovative and creative way that will lead into discussion and exchanging ideas and thoughts. Finally, complementary approach is when the ICT is used to aid and support the student's learning. This approach allows students to be more organized and efficient in which they can obtain 
the notes from computer, submit their work by e-mail from home as long as they meet the deadline. They will also search for information from various online sources to fulfil the task given to them (Hermans, et al., 2008).

The Kenya Institute of Curriculum Development (KICD) has embraced OER in instruction and in conjunction with the Ministry of Education is in the process of rolling out a new Competence Based Curriculum (CBC) which advocates for critical thinking, creativity and digital literacy (Orwenjo \& Erastus, 2018). All this is geared towards an educational system that is in tandem with the global requirement of replacing traditional teaching methods with a technology-based teaching and learning, tools and facilities. However, in Kenya there lacks a serious policy framework that institutionalises the uptake and implementation of TBI and OER in educational institutions at all levels. Kenya has also failed to institutionalise the concept of the Open University and individual institutions of higher learning have been left to map their own strategies to set up schools and develop curriculums that embrace the concept of open learning so as to position and align themselves competitively on the global front. One natural consequence of this is lack of a policy on human resource training regarding the use of TBI and OER, and individual lecturers, with very few exceptions, are left to take personal initiatives to self-develop themselves in order to be relevant and operate in a world that is increasingly becoming technology-driven. Another consequence is the failure by universities to provide requisite infrastructure for the uptake and utilisation of technology for both learners and instructors. This paper discusses the levels of preparedness among Kenyan lecturers in embracing technology for content delivery in their classrooms.

\section{Theoretical Framework}

This paper was developed based on the guidance of two theories: Human Capital theory, (Schultz, 1981) and Educational Production Functions (Coleman, 1965). Human Capital theory posits that human capital consists of knowledge, skills and abilities of the people employed in an organisation. Bontis, et al., (2001) define human capital as the individual knowledge stock of an organisation as represented by its employees-the human factor in the organisation; the combined intelligence, skills and expertise that give the organisation its distinctive character. Competence includes skills and education, while attitude covers the behavioural component of the employees' work. Intellectual agility enables one to change practices and to think of innovative solutions to problems. Human capital therefore signifies any stock of knowledge or characteristics the worker has, either innate or acquired, that contribute to his or her productivity. This theory has been employed in this paper in commentaries on the abilities of teachers to utilise and implement OERs in instruction. The Education Production Function theory as applied in education examines the relationship among the different inputs into the educational process and outcomes of the process. It relates various inputs affecting a student's learning, for example schools, families, peers and neighbourhoods to measured outputs including subsequent labour market success, college attendance, graduation rates, and, most frequently, standardized test scores. This theory has been applied in this paper with regard to data related to availability of teaching/learning resources and the infrastructural support within and around the school.

\section{Methodology}

The study was carried out in selected public universities in Kenya. The study was conducted using ex post facto research design to determine the perception and use of education technologies by 8,000 academic staff in public universities in Kenya. The study classified public universities into two: old and newly established universities. The seven old universities in Kenya had been established before the year 2000. The new ones were established after the year 2000. Two out of the seven old universities, and five out of the new universities were randomly chosen for the study. From a population of 10,000, Kathuri and Pals (1993) recommend a sample size of 370.

The study used structured questionnaires to collect primary data. Faculty members who are experts in educational technology reviewed the questionnaire to improve on its face and content validity. The questionnaire was also considered reliable after obtaining a reliability coefficient of 0.79 , which is above the minimum threshold reliability coefficient (of 0.7) as advised by Mugenda and Mugenda (1999). Although the determined sample size was 370 , to cater for unresponsiveness, four hundred questionnaires were then either posted via email or delivered to the selected respondents who had two weeks to fill the questionnaires. The filled questionnaires were either posted via email or collected as mutually agreed. Three hundred and eighty two filled questionnaires were returned and were complete in aspects but 370 were considered for further analysis.

The questionnaire was designed to obtain information on the academic staff's age, gender, current designation, teaching experience, their perception about adequacy of facilities and use technologies in education. The collected data was cleaned and keyed in for analysis aided by Statistical Package for Social Sciences (SPSS) version 22 for windows.

\section{Findings}

The findings of this study have been presented under the state of events amongst academic staff in Kenya's public universities regarding their abilities to offer technology-supported instructions and their attitudes towards the same. Also presented are findings regarding institutional and infrastructural challenges that hinder uptake and rolling out 
of OER in Kenya's public universities.

\subsection{Uptake of Technology-based Instruction and OER}

The academic staff in Kenya's public universities embrace technology in the following areas:

\subsubsection{Course Preparation}

A great majority (58.4\%) of the academic staff reported using their mobile phones, I-pads, tablets, laptops and desktops to access worldwide web resources to enhance their lecture notes. This they mostly did before getting to the lecture hall, but once in a while some accessed the web-based resources even as a lecture was ongoing if they felt an inadequacy that could be addressed by going online.

\subsubsection{Actual Classroom Teaching}

The academic staff have embraced the use of technology for actual instruction in a number of ways. Firstly, $46 \%$ of the lecturers declared to have abandoned hard copy lesson notes in favour of soft copies carried on their mobile phones, I-pads, tablets and portable laptops. Secondly, $41 \%$ of the lecturers admitted to sending soft copies of lecture notes to students prior to their meeting via their emails or mobile phone Whatsapp platform. This, they said, promoted access and attention especially in very large classes where they were not sure very students could hear them in large rooms without public address devices.

About half $(51.4 \%)$ of the lecturers of language admitted to have used the online dictionary in real time to confirm the pronunciations of words. Slightly more than half $(52.4 \%)$ of lecturers in other fields, reportedly accessed the web-based resources for figures, diagrams and other visual information that they felt would promote the content learning. More so, $48 \%$ of the lecturers used power-point presentations where possible. They claimed this kind of presentation kept the students more attentive and receptive to the content. This agrees with Ghavifekr and Rosdy's (2015) observation that almost all ranges of subjects can be learned more effectively through technology-based tools and equipment.

\subsubsection{Evaluation and Assessment}

In acknowledgement of the large volumes of information available online on all areas of knowledge, $56.7 \%$ of the lecturers across the divide admitted to giving students assignments regarding the writing of term papers on barely introduced topics. The students will be expected, therefore to use the web-based resources in doing the assignments. As Finger \& Trinidad (2002) observe, such use of ICT in teaching enhances the learning process and maximizes the students' abilities in active learning as they have to be fully involved in the process of knowledge discovery, evaluation and analysis. In addition, 33\% of the lecturers declared that they no longer expected hard copy documents from their graduate students. In this case, the graduate students submitted their documents (Masters or Ph.D. proposals/concept papers, term papers) via email and the lecturer in turn made their corrections and comments on the soft documents. Hermans, et al., (2008) document this as part of the complementary function of ICT. However, since this requires some level of proficiency in ICT use on their part, some $56 \%$ of the lecturers opined that use of hard copies was better. Furthermore, lecturers noted that the large number of students in undergraduate classes discouraged this kind of interaction.

\section{Challenges in Uptake of Technology Based Instruction (TBI)}

This section discusses the challenges that hinder the uptake and utilisation of TBI among academic staff in Kenya's public universities. The challenges are two-fold: lecturer-based challenges and infrastructure-based challenges.

\section{1: Lecturer-based challenges}

The section presents challenges that are based on the academic staff are discussed as follows.

\subsubsection{Lack of Awareness}

About $22.4 \%$ of the academic were unaware of OER. Having not been beneficiaries of such resources themselves they came into the field with a fixated mindset of traditional texts as the only source of educational learning. They admitted to knowing that there is a lot of information on just about everything on the internet but they were not aware that part of that information could actually help them in delivering their subject content to their learners. This is especially the case with the long-serving older academic staff. These finding concur with those of a study by Bateman (2006) amongst university students and lecturers whereby nearly every respondent was 'unfamiliar' with the concept of OER. A small number (13\%) of academic staff is also completely ignorant of the concept of the Open University and how one can, for example, conduct instruction on a virtual platform by use of technology. More than a third (38.6\%) of the academic staff are aware of availability of OER and the possibility of technologybased instruction but they do not know how to go about the utilisation or embracing these resources.

\subsubsection{Poor ICT Skills}

Less than half (42.4\%) of the academic staff in Kenya have high ICT abilities that empower them to offer TBI in an optimal way (either in a physical or on a virtual platform, and actually embraced the same in day to day instruction). However, more than half (58\%) of the respondents had basic computer skills and rated their computer skills as either excellent or good. They possessed enough ICT knowhow to perform such tasks as operating their 
smart mobile phones and visiting search engines for information search and retrieval. About half of these lecturers reported to have self-taught themselves in ICT skills. This is because they were products of the Kenyan education system where at all levels of instruction, the computer-student ratio is very low therefore, very little, if any, meaningful computer-based learning can take place (Chapelle, 2011, Kinyua, 2019). Almost half (48\%) of the academic staff admitted to having very poor ICT skills. The computing skills they had acquired were as a matter of necessity as they strove to acquire higher education. As a result, their ICT abilities were selective, based on what was relevant in the course of their studies. While $23 \%$ of the academic staff were proficient at Microsoft Word applications, they were incompetent at MS Excel or MS PowerPoint, and a further 14.8\%, while acknowledging awareness of the same, were actually ignorant as to the equipment they would require to successfully deliver content via Microsoft PowerPoint, for example.

\subsubsection{Negative Attitudes}

One hurdle to the implementation of TBI and OER is the poor attitude some lecturers have towards the resources. About $44.1 \%$ of the respondents felt that OERs are tedious and time consuming. Being products of the teachercentred methods of teaching, many lecturers may fail to appreciate the research-supported advantages of technology as an aid to classroom learning, therefore they do not even consider the possibility of embracing it. Additionally, in an environment with poor institutional support, lecturers find it an unnecessary bother to, for example, try to secure the equipment necessary for a PowerPoint-aided classroom delivery. More so, the equipment may not be available exactly when required so they abandon the idea altogether. Regarding the utilisation of OER the $87.8 \%$ of the lecturers decried the large numbers of students that cannot be accommodated in the regular computer rooms at certain universities, even if the rooms were available for use.

\subsubsection{High Cost of training}

More than a third (39\%) of the respondents indicated a desire to upgrade their ICT skills, especially to be able to offer TBI in a competent way, in accordance with the global trends. However, while bemoaning the fact that many universities in Kenya lack the capacity to offer world-class training in educational technology, $44 \%$ of the respondents cited the high cost of taking the necessary courses through online classes being offered by other universities that are established in the discipline.

\subsection{Infrastructural Challenges}

Infrastructure provides the necessary support for TBI. The study discusses some of the challenges regarding infrastructure as follows:

\subsubsection{Inadequate Facilities}

Uptake of technology-based instruction and utilisation of OER must be supported by relevant infrastructure. On the one hand the lecturers who have capacity to use TBI methods can do so only if the universities provide the equipment that can enable the same. On the other hand, as Bateman (2006) observed, OERs are open and free only theoretically because in reality, especially in the developing world, these resources are neither open nor free to those unable to access the basic yet necessary infrastructure: electricity, computers with affordable software and the internet. An overwhelming majority $(96.7 \%)$ of the respondents decried inadequate infrastructure to support TBI.

In recent years in Kenya, many universities have opened satellite campuses in an effort to expand their reach and to respond to the demand for higher education. Unfortunately, many of these campuses have been set up in a hurried manner, so that in some cases the lecture room is just an open space with no power sockets where a lecturer could plug in equipment for a TBI session. Many of these campuses have since been closed by a ministerial directive. More so, in many universities in Kenya, internet access for lecturers and learners is limited to $\mathrm{Wi}-\mathrm{Fi}$ connection in hotspots created in strategic points on university premises. This means lecture halls and offices lack internet connectivity. This reduces the lecturer's advantage in, for example, visiting the web for content that could enrich his/her lesson. At the same time this removes the opportunity of an OER interaction in a lecture hall even where students may have their own laptops. Hennessy, Ruthven and Brindley (2005) note that a key factor in use of ICT is sufficient computer labs and ICT equipment so as to ensure that subject teachers and learners have easy access to ICT tools whenever needed.

\subsubsection{Poor Institutional Support}

All the respondents reported not to have a policy on TBI or even OERs at their universities. While discussing the use of OER in universities, Bateman (2006) laments the lack of concrete structures to see to their implementation. In Kenya, the concept of the Open University, for example, at least on the national platform, remains a proposal. Individual university managements in Kenya have had to take responsibility to introduce the open learning schools, at their own cost. Unfortunately, in an environment with competing interests and reduced funding, university managements have failed to or lack the capacity to invest in the equipment and infrastructure requisite for effective TBI, as well as to create an infrastructural environment conducive for OER utilisation among lecturers and learners. 


\section{Discussion of Findings}

One thing that was very clear from the findings of this paper is that over $15 \%$ of lecturers out in the field in Kenya are ignorant of the concept of TBI and OER. This proportion can frustrate the benefits associated with TBI and OER. Furthermore, some lecturers who are aware of the TBI and OER lack ICT skills to be able to effectively use them. In the light of Human Capital theory this is a pointer towards less productivity owing to lack of knowledge and expertise of the lecturers, which calls for action on the part of the education managers: Firstly, there is a need to do in-service training to sensitise the academic staff on the existence and importance of TBI and OER. Secondly, it is imperative that this in-service training extends to equipping all academic staff with a high measure of ICT competence that would ensure their participation in adoption of TBI and utilisation of OERs. This in the long run will update the workforce for more productivity.

The Education Production Function theory relates the different inputs into the educational process and outcomes of the process. The findings of this study reveal that in order to promote learning in Kenya's universities, there is real need to upgrade facilities within the universities and campuses to give the lecturers and learners an opportunity to use and benefit from TBI and OER. United Nations Sustainable Development Goal No. 4 cites reasons for lack of quality education as lack of adequately trained teachers, poor conditions of schools and equity issues related to opportunities provided to rural children (UNDP, 2016). Kenya being a member state should show commitment to this ideal by ending the tokenism mentality evident in policy formulation without implementation and follow-up. Apart from ensuring electricity and internet connectivity throughout the country, specifically in the remote parts of Kenya, funding of institutions of learning at all levels should be enhanced so as to ensure that every institution has proper, functional and well equipped lecture halls and computer rooms. There should also be a policy framework guiding university expansion so as to check the proliferation of university campuses that lack both adequate human resource and facilities to aid instruction.

\section{Conclusions}

By embracing the use of TBI and OER the Ministry of Education in Kenya through KICD has taken a step in the right direction. However, there is need to follow up policy with implementation so that there is a policy framework that supports the empowerment of universities to acquire, roll out and utilise these resources. In accordance with the global trends, Kenya should adopt the concept of open learning and be ready to facilitate its implementation by way of funding the start-up institution and funding the existing institutions well enough so that they may acquire the infrastructure necessary for adoption of TBI and OER. There is also need for training and upgrading their human resource to be able to embrace the new methods of instruction in order to promote learning among their charges. In turn, the instructors should recognise and appreciate TBI and OER as a useful supplement to their traditional teaching resources. The lecturers must be willing to align themselves in the direction the educational world is going by actively updating their ICT skills and making efforts to integrate TBI and OER resources in imparting knowledge to their learners. This will help in steering the country in the direction of the global requirement of shifting from traditional methods of instruction to more effective technology-aided instruction methods.

\section{REFERENCES}

Bateman, P. (2006). Discussion Paper: The AVU Open Educational Resources (OER) Architecture for Higher Education in Africa. OECD Expert Meeting - Barcelona.

Chapelle, C. (2011). Computer Applications in Second Language Acquisition: Foundations for Teaching, Testing and Research. Cambridge: Cambridge University Press.

Devlin, Timothy J.; Feldhaus, Charles R.; Bentrem, Kristin M. (2013). The Evolving Classroom: A Study of Traditional and Technology-Based Instruction in a STEM Classroom. Journal of Technology Education, v25 n1 p34-54 Fall

Finger, G., \& Trinidad, S. (2002). ICTs for learning: An overview of systemic initiatives in the Australian states and territories. Australian Educational Computing, 17(2), 3-14.

Ghavifekr, S. \& Rosdy, W.A.W. (2015). Teaching and learning with technology: Effectiveness of ICT integration in schools. International Journal of Research in Education and Science (IJRES), 1(2), 175-191.

Grabe, M., \& Grabe, C. (2007). Integrating Technology for Meaningful Learning (5th ed.). Boston, MA: Houghton Mifflin

Hermans, R., Tondeur, J. , Van -Braak, J., \& Valcke, M. (2008). The impact of primary school teachers' educational beliefs on the classroom use of computers. Computers \& Education, 51(4), 1499-1509.

Hennessy, S., Ruthven, K. \& Brindley, S. (2005). Teacher perspectives on integrating ICT into subject teaching: commitment, constraints, caution, and change. Journal of Curriculum Studies, 37(2), 155-192. http://dx.doi.org/10.1080/0022027032000276961.

Kathuri, N. J. \& Pals, D. A. (1993). Introduction to Educational Research. Njoro: Egerton University.

Kinyua, A. H. G. (2019). (2019)When the Trainer is Untrained: Stakeholder Incapacitation in Implementation and 
Utilisation of Open Educational Resources in Kenya. Paper presented at the Pan Commonwealth Forum on $9^{\text {th }}-12^{\text {th }}$ September, 2019, Edinburgh.

Mugenda, O. M. \& Mugenda, A. G. (1999). Research Methods: Quantitative and Qualitative Approaches. Nairobi : Act press.

Orwenjo, D.O., \& Erastus, F.K. (2018). Challenges of Adopting Open Educational Resources (OER) in Kenyan Secondary School: The Case of Open Resources for English Language Teaching (ORELT). Journal of Learning for Development, 5(2), 148-162.

Robinson, Rhonda; Molenda, Michael; Rezabek, Landra. "Facilitating Learning" (PDF). Association for Educational Communications and Technology.

United Nations Development Programme (2016). Sustainable Development Goals. Author. Available on https://sustainabledevelopment.un.org/ Accessed on $28^{\text {th }}$ June 2019 